\title{
14-3-3 $\beta$ protein expression in eosinophilic meningitis caused by Angiostrongylus cantonensis infection
}

Hung-Chin Tsai ${ }^{12^{*}}$, Yen-Lin Huang ${ }^{3}$, Yao-Shen Chen ${ }^{1,2}$, Chuan-Min Yen ${ }^{4}$, Rachel Tsai ${ }^{3}$, Susan Shin-Jung Lee ${ }^{1,2}$ and Ming-Hong Tai ${ }^{3^{*}}$

\begin{abstract}
Background: Angiostrongylus cantonensis is a parasite endemic in the Southeast Asian and Pacific regions. Humans are incidentally infected either by eating uncooked intermediate hosts or by consuming vegetables containing the living third-stage larvae. The 14-3-3 $\beta$ protein is a cerebrospinal fluid (CSF) marker of neuronal damage during the development of Creutzfeldt-Jakob disease. In addition, increased 14-3-3 $\beta$ protein is also found in CSF from patients with a variety of neurological disorders. The goal of this study is to determine the roles of serum/CSF14-3-3 $\beta$ protein in patients with eosinophilic meningitis.

Methods: In a cohort study among nine Thai laborers with eosinophilic meningitis due to eating raw snails (Pomacea canaliculata), we examined the CSF weekly while patients were still hospitalized and followed up the serum for 6 months. The levels of 14-3-3 $\beta$ protein in CSF were analyzed by western blot and an in-house 14-3-3 $\beta$ enzyme-linked immunosorbent assay (ELISA) measurement was established and tested in an animal model of eosinophilic meningitis.
\end{abstract}

Results: The elevated 14-3-3 $\beta$ level was detected in the CSF from eight out of nine (81\%) patients After 2 weeks of treatment, all patients showed a declined level or cleared of 14-3-3 3 protein in the CSF. By developing an in-house ELISA for measurement of $14-3-3 \beta$ protein, it was found that the serum 14-3-3 $\beta$ level was significantly increased in patients during initial visit. This finding was consistent to the animal experiment result in which there was severe blood brain barrier damage three weeks after infection and increased 14-3-3 $\beta$ protein expression in the CSF and serum by western blot and in house ELISA. After treatment, the serum 14-3-3 $\beta$ level in meningitis patients was rapidly returned to normal threshold. There was a correlation between initial CSF 14-3-3 $\beta$ level with severity of headache $(r=0.692, p=0.039)$, CSF pleocytosis $(r=0.807, p=0.009)$ and eosinophilia $(r=0.798, p=0.01)$ in the CSF of patients with eosinophilic meningitis (Spearman's correlation test).

Conclusions: The serum 14-3-3 $\beta$ concentrations may constitute a useful marker for blood brain barrier damage severity and follow up in patients with eosinophilic meningitis caused by $A$. cantonensis.

Keywords: Angiostrongylus cantonensis, Eosinophilic meningitis, 14-3-3 $\beta$ protein

\footnotetext{
*Correspondence: hctsai1011@yahoo.com.tw; minghongtai@gmail.com

${ }^{1}$ Section of Infectious Diseases, Department of Medicine, Kaohsiung Veterans

General Hospital, 386, Ta-Chung 1st Road, Kaohsiung 813, Taiwan

${ }^{3}$ Institute of Biomedical Sciences, National Sun Yat-Sen University, Kaohisung,

Taiwan, Republic of China

Full list of author information is available at the end of the article
}

\section{Biomed Central}

(c) 2014 Tsai et al.; licensee BioMed Central Ltd. This is an Open Access article distributed under the terms of the Creative Commons Attribution License (http://creativecommons.org/licenses/by/2.0), which permits unrestricted use, distribution, and reproduction in any medium, provided the original work is properly credited. 


\section{Background}

The major cause of eosinophilic meningitis in the Pacific Islands and Southeast Asia is Angiostrongylus cantonensis, also known as the rat lungworm [1-4]. Humans are infected with $A$. cantonensis by ingesting freshwater, terrestrial snails and slugs [5-8]. The major intermediate hosts for $A$. cantonensis in Taiwan are the African giant snail (Achutina fulica) and the golden apple snail (Pomacea canaliculata) $[5,8]$. Pomacea canaliculata was introduced to Taiwan in 1979 as a food source. It spread widely in paddy fields and drainage ditches and has become an important cause of outbreaks of eosinophilic meningitis [8]. Three outbreaks of eosinophilic meningitis caused by $A$. cantonensis occurred in Kaohsiung, Taiwan, in 1998, 1999 and 2001, respectively [9-11]. Most patients $(17 / 22,77 \%)$ were adult male, Thai laborers who had eaten raw golden apple snails approximately 1 to 3 weeks earlier before hospitalization.

The presence of 14-3-3 protein in cerebrospinal fluid (CSF) has been found to have significant in vivo diagnostic properties in patients with Creutzfeldt-Jakob disease (CJD) [12], and it is thought to result from neuronal disruption and the leakage of brain proteins into the CSF [13]. This protein was found in CSF specimens obtained from patients with various neurological pathologies whose common feature was the presence of some degree of neuronal loss [14-17]. Although its lack of specificity clearly implies substantial limitations in the use of 14-33 protein as a specific CJD marker, its value as an indicator of neurological damage could be used to monitor the evolution of different neurological disorders with etiologies that can be otherwise established. Furthermore, the 14-3-3 protein was recently found to be reacted with 31$\mathrm{kDa}$ antigen in A. cantonensis infection [18]. Therefore, it was possible to use this protein as a diagnostic tool in A. cantonensis infection.

Based on this hypothesis, we studied the dynamic changes of 14-3-3 $\beta$ protein expression in the second outbreak, correlated with CSF findings and established the measurement of $14-3-3 \beta$ protein expression by enzyme-linked immunosorbent assay (ELISA) and tested in an animal model of eosinophilic meningitis.

\section{Methods}

\section{Ethics statement}

All of the samples of human patients (A to I) were obtained from an outbreak of eosinophilic meningitis in 1999. Those samples were collected at the research laboratory of Infectious Diseases Department, Kaohsiung Veterans General Hospital (KVGH) and the patient's information was delinked. Institutional review board (IRB) approval to use the samples was obtained from the Commission on Medical Ethics of the Kaohsiung Veterans General Hospital (VGHKS98-CT8-07). All participants were informed about the study procedures and gave their written informed consent initially when the outbreak occurred. Animal studies were carried out in strict accordance with the recommendations from Taiwan's Animal Protection Act. The protocol was approved by the Animal Committee of the Kaohsiung Veterans General Hospital.

\section{Study population}

A case of eosinophilic meningitis was clinically defined as an acute onset of headache, eosinophil pleocytosis in the blood/CSF, accompanied by at least of one of the following: fever, ataxia, visual disturbances, photophobia, nuchal rigidity, neck pain, hyperesthesias, or paresthesias [10]. All patients who had eaten raw snails within 3 weeks of the outbreak's onset were included in the study. We recorded demographic information, the date of snails were eaten and the amount ingested, clinical symptoms, and prior parasitic infections. Each patient underwent a physical, neurologic, and ophthalmic examination. The headache intensity was rated on a 4-point scale ranging from none to severe $(0=$ none, $1+=$ mild, $2+=$ moderate, $3+=$ severe) [10]. The hyperintense basal ganglia lesion on T1-weighted MRI was also graded as a 4-point scale ranging from none to severe by 2 independent radiologists [10]. Spinal taps were performed on all patients. The patients were observed daily during their hospital course. CSF was examined weekly. Peripheral blood was obtained weekly for the first 2 months, every other week for the next 2 months, and monthly thereafter for as long as 6 months. Antibodies to A. cantonensis were detected in serum and CSF by a microenzymelinked immunosorbent assay (ELISA) using young-adult worm antigen, molecular weight $204 \mathrm{kDa}$ purified by monoclonal antibody [19].

\section{Infection of Balb/C mice with third stage larvae of $A$. cantonensis}

Twenty-four Balb/C mice, aged 6-7 weeks, were purchased from the National Laboratory Animal Breeding Research Centre. They were raised and maintained in an air-conditioned animal facility $\left(25 \pm 2{ }^{\circ} \mathrm{C}\right.$ and $50 \pm 10 \%$ relative humidity). Third-stage larvae of $A$. cantonensis were harvested from infected Biomphalaria glabrata after treatment with artificial gastric juice (pepsin, 2 g; concentrated $\mathrm{HCl}, 7 \mathrm{~mL}$; distilled water, $1 \mathrm{~L}$ ). Mice were orally infected with $50 \mathrm{~A}$. cantonensis L3 via an orogastric tube after slight ether anesthesia and then mice were euthanized every week for 3 consecutive weeks after infection.

\section{Collection of serum and CSF specimens}

Blood samples from experimental mice were collected by a heart puncture under ketamine anesthesia. Serum specimens separated from blood samples after centrifugation 
at $3500 \times g$ (Hermle, Z326K, Germany) for 5 min at $4^{\circ} \mathrm{C}$ were stored at $-70^{\circ} \mathrm{C}$ until they were measured.

The skull of the mice was opened after complete bleeding. Careful surgery was conducted in order to avoid blood contamination of the CSF. The brain was removed and washed with $50 \mu \mathrm{L} 0.15 \mathrm{M}$ phosphate buffered saline (PBS). Concurrently, the cerebral ventricles and cranial cavity were washed with $350 \mu \mathrm{L}$ PBS. The CSF was, thus, harvested with PBS from above, which was then centrifuged in an eppendorf tube at $3000 \times g$ (Hermle, Z326K, Germany) for $10 \mathrm{~min}$ at $4^{\circ} \mathrm{C}$ to eliminate cells. The supernatant was stored at $-70^{\circ} \mathrm{C}$ until further use.

\section{Measurement of permeability of the blood-brain barrier by Evans blue method}

Evans blue was used to assess the permeability of the blood-brain barrier to macromolecules. When the blood-brain barrier had been compromised, albuminbound Evans blue entered the CNS. In brief, a volume of $200 \mu \mathrm{L}$ of $2 \%(\mathrm{w} / \mathrm{v})$ solution of Evans blue in PBS was injected into the tail vein of a mouse. One hour later the brain of the mouse was removed after anesthesia with ketamine, which was ground with $1.0 \mathrm{~mL}$ PBS in a glasstissue grinder with a Teflon pestle. The extract was then centrifuged at $18,000 \times g$ (Hermle, Z326K, Germany) for $10 \mathrm{~min}$ at room temperature. The optical density (OD) of the supernatant was read at $595 \mathrm{~nm}$ wavelength using a colorimeter (Thermo scientific multiskan FC, USA). Then the OD values of mice brain supernatant after 1 to 3 weeks infections were compared with the control.

\section{Measurement of 14-3-3 $\beta$ protein concentrations in CSF/serum by Western blot analysis}

CSF/serum aliquots of $100 \mu \mathrm{L}$ from 9 patients and mice were mixed with 7 volumes of cold methanol, kept at $-20^{\circ} \mathrm{C}$ for $2 \mathrm{~h}$, and then centrifuged at $20,800 \mathrm{~g}$ for $30 \mathrm{~min}$. The pellet was dissolved in $40 \mu \mathrm{L}$ of sample buffer (3\% SDS, 3\% $\beta$-mercaptoethanol, 2 mM EDTA, 10\% glycerol, and $62.5 \mathrm{mM}$ Tris, $\mathrm{pH}, 6.8$ ) and boiled for $5 \mathrm{~min}$. For each sample, $10 \mu \mathrm{L}$ (the equivalent of $25 \mu \mathrm{L}$ of CSF), $5 \mathrm{~mL}$, and $1.25 \mathrm{~mL}$ of sample buffer/well were loaded onto a $13 \%$ polyacrylamide gel and transferred to polyvinyliden difluoride membranes (Immobilon P; Millipore). Membranes were incubated with anti 14-3-3 $\beta$ polyclonal rabbit IgG (Santa Cruz Biotechnology) at a 1:500 dilution and revealed with anti-rabbit horseradish peroxidase IgG (Amersham) at a 1:3000 dilution. The blots were developed using an enhanced chemiluminescent system (Amersham). Densitometric values for each sample were obtained with a computer-assisted laser scanner (GS-710 Calibrated Imaging Densitometry; BioRad), after correction for background. The total amount of 14-3-3 protein as quantified from each diluted and undiluted CSF sample was expressed in arbitrary units [19]. The human control group ( $\mathrm{n}=9)$, matched for age and gender, consisted of patients with headache or altered consciousness who underwent lumbar puncture to exclude meningitis. CSF samples were centrifuged and the supernatants were frozen at $-80^{\circ} \mathrm{C}$ until assayed.

\section{Generation of recombinant 14-3-3 $\beta$}

Recombinant human 14-3-3 $\beta$ protein was purified from $E$. coli for antibodies generation as previously described [20]. The human 14-3-3 $\beta$ cDNA was amplified from a human fetal brain cDNA library (Stratagene, La Jolla, CA) using the polymerase chain reaction (PCR). The PCR primers used to clone the human 14-3-3 $\beta$ cDNA were designed based on the 14-3-3 $\beta$ sequence in the Gen-Bank database (accession number, NM_003404.3; forward primer, 5'cgcggatccatgacaatggataaaagtgagctg $-3^{\prime}$; reverse primer, $5^{\prime}$ ggcgaattcttagttctctccctccccagc-3'). After DNA sequencing analysis, the PCR-amplified 14-3-3 $\beta$ cDNA was subcloned into the EcoRI and BamHI sites of the pET28a vector (Novagen, Madison, WI) and transformed into BL-21 cells (DE3, pLysS; Novagen). After induction, the 6x-histidinetagged 14-3-3 $\beta$ protein was purified on an NTA-agarose affinity column (Qiagen, Hilden, Germany) and desalted on a G25 Sephadex column (Amersham Pharmacia, Little Chalfont, United Kingdom). The recombinant protein was passed through Detoxi-Gel (Pierce Biotechnology, Rockford, IL) to minimize contamination by endotoxin. The $14-3-3 \beta$ antibodies were raised by periodic injection of recombinant $14-3-3 \beta$ protein into rabbits. The serum was collected from immunized rabbits and analyzed using Western blot analysis.

\section{Production of anti-human 14-3-3 $\beta$ polyclonal antisera Primary immunization}

Purified recombinant $14-3-3 \beta$ protein in PBS $(500 \mu \mathrm{g}$ in $500 \mu \mathrm{l})$ is mixed with complete Freunds adjuvant in a three-way stopcock until mixture becomes emulsified. The mixture is then transferred to a $3 \mathrm{ml} 24$-gauge syringe and was injected subcutaneously into adult New Zealand white rabbits (2 to $5 \mathrm{~kg}$ body weight) under restrain. Two weeks after the primary immunization, the rabbits were then boosted with recombinant 14-3-3 $\beta$ protein mixed with incomplete Freunds adjuvant at 2week intervals for a total of nine boosts.

\section{Blood serum preparation}

Blood was collected from the ear marginal veins of restrained rabbits before immunization (pre-immune serum) and after subsequent boosts for a total of six batches. About $50 \mathrm{ml}$ of blood was collected during each interval. After removing blood clots, the serum samples were placed overnight in $4^{\circ} \mathrm{C}$ and centrifuged 10 minutes at 5,000 $\mathrm{g}$ to remove red blood cell pellets and other cell 
debris. The samples were stored at $-70^{\circ} \mathrm{C}$ prior to purification.

\section{Antibody purification}

Serum samples containing 14-3-3 $\beta$ antibodies were purified using Protein A column (Pharmacia Biotech) and quantified with Coomassie Plus Bradford assay kit (Pierce, \#23236). Antibody efficacy was checked with Western blot analysis using recombinant $14-3-3 \beta$ protein at concentration of $1,0.1$ and $0.01 \mathrm{ug} / \mathrm{ml}$.

\section{4-3-3 $\beta$ enzyme-linked immunosorbent assay (ELISA)}

The in-house 14-3-3 $\beta$ ELISA consisted of rabbit anti-14$3-3 \beta$ polyclonal antibody as the capture antibody and mouse anti-14-3-3 $\beta$ IgG conjugated with horse-radish peroxidase (Santa Cruz Biotechnologies Inc.; sc-1657 HRP (H-8), $200 \mu \mathrm{g} / \mathrm{ml}$ ) as the detection antibody, with the purified recombinant $14-3-3 \beta$ protein as standard. Briefly, 96-well plate were coated with $50 \mu \mathrm{l}$ per well of diluted capture antibody $(2.5 \mu \mathrm{g} / \mathrm{ml})$ overnight at $4^{\circ} \mathrm{C}$. After washing with buffer containing $0.05 \%$ Tween 20 in PBS, wells were blocked with buffer containing 0.05\% Tween 20, 0.1\% BSA, 5\% sucrose in PBS at room temperature for $30 \mathrm{~min}$. The CSF/serum samples $(50 \mu \mathrm{l})$ or standards were applied to wells and incubated at room temperature for 1 hour. After wash, the wells were incubated with detection antibody (mouse anti-14-3-3 $\beta$, $1 \mu \mathrm{g} / \mathrm{ml}$ ) at room temperature for 1 hour. Finally, $100 \mu \mathrm{l}$ of TMB substrate solutions were added and reacted at room temperature for $20 \mathrm{~min}$. After adding $50 \mu \mathrm{l}$ of $2 \mathrm{~N}$ $\mathrm{H}_{2} \mathrm{SO}_{4}$, the optical density in each well was measured at $450 \mathrm{~nm}$ using an ELISA reader.

\section{Statistical analysis}

The relation between the amount of $14-3-3 \beta$ protein in CSF, laboratory abnormalities, and clinical severity and MRI findings were analyzed with Spearman's correlation coefficient test. Wilcoxon signed-rank test was used to compare the change of 14-3-3 $\beta$ protein in every week of lumbar puncture. Mann Whitney $U$ test was used to compare the changes of $14-3-3 \beta$ protein or Evans blue in third week relative to the controls. A $P$ value $<0.05$ was considered statistically significant.

\section{Results}

In the current studies, all nine patients were young Thai men. The source of epidemic was ingestion of raw snails seasoned with lemon juice and red pepper. Antibodies to $A$. cantonensis were detected at the time of admission in the serum of $9(100 \%)$ patients and in the cerebrospinal fluid of 4 (44\%) patients. Patients in this outbreak in 1999 only received supportive therapy (acetaminophen and naproxen), lumbar puncture was done when clinically indicated. None received steroid treatment. All of the nine patients received a total of 23 lumbar punctures. Patient F received a total of 3 lumbar punctures. Patient $C$ and I have 4 lumbar punctures due to recurrent symptoms. Headache, stiff neck, transient right facial palsy, ataxia, and diplopia recurred in patient $\mathrm{C}$ 2 weeks after last admission; he was treated with intravenous glycerol for 7 days and recovered completely. Vomiting and headache developed in patient I 3 weeks after admission and a spinal tap revealed an elevated opening pressure of $240 \mathrm{~mm} \mathrm{H}_{2} \mathrm{O}$, a white cell count of $1110 \times 10^{3}$ cells per $\mu \mathrm{L}$ with $74 \%$ eosinophils. He recovered without treatment in about a week.

The Western blot analysis for 14-3-3 $\beta$ protein in CSF was shown in Figure 1. Eight out of nine patients had a Detectable 14-3-3 $\beta$ protein in CSF at admission. The initial 14-3-3 $\beta$ protein amount in CSF, severity of headache, laboratory abnormalities, and findings in the brain MRI scan are listed for each patient in Table 1 . There was a correlation between initial CSF 14-3-3 $\beta$ level with severity of headache $(r=0.692, p=0.039)$, CSF pleocytosis $(r=0.807, p=0.009)$, and CSF eosinophilia $(r=0.798$, $\mathrm{p}=0.01$ ) in patients with eosinophilic meningitis (Spearman's correlation test). Wilcoxon signed-rank test was used to compare the change of $14-3-3 \beta$ protein in each lumbar puncture and it revealed there was a significant decrease of 14-3-3 protein amounts in the $2^{\text {nd }}$ week (one week) after admission (Wilcoxon signed-rank test, $\mathrm{p}=$ 0.025). Patient $C$ and I had only mild elevation of 14-3-3 protein when recurrence of symptoms. Nine patients with a diagnosis of sepsis underwent lumbar puncture for excluding meningitis as control group all showed negative $14-3-3 \beta$ protein expression in CSF and serum.

\section{Detection of 14-3-3 $\beta$ levels in patient CSF/Serum samples} Using polyclonal antibodies constructed from rabbit immunized with recombinant 14-3-3 $\beta$ antigen, we have established a procedure to detect 14-3-3 $\beta$ levels in CSF and serum using ELISA. We have found that the level of $14-3-3 \beta$ protein in the patient serum decreased over an eight week period after on admission to the hospital (Figure 2). There was a near four-fold reduction of the protein at about two weeks after the first lumbar puncture (Wilcoxon signed-rank test, $\mathrm{p}=0.012$ ). However, we did not observe significant changes in the CSF samples due to the inadequate samples numbers and CSF volumes.

\section{Permeability of the blood-brain barrier by Evans blue method in the animal study}

Uninfected control mice with the optical density of the extract of the brain measured at $595 \mathrm{~nm}$ were similar with the blank control. In contrast, the brain of infected mice showed varying degrees of staining by Evans blue after infection. The amount of Evans blue in the mice brain 


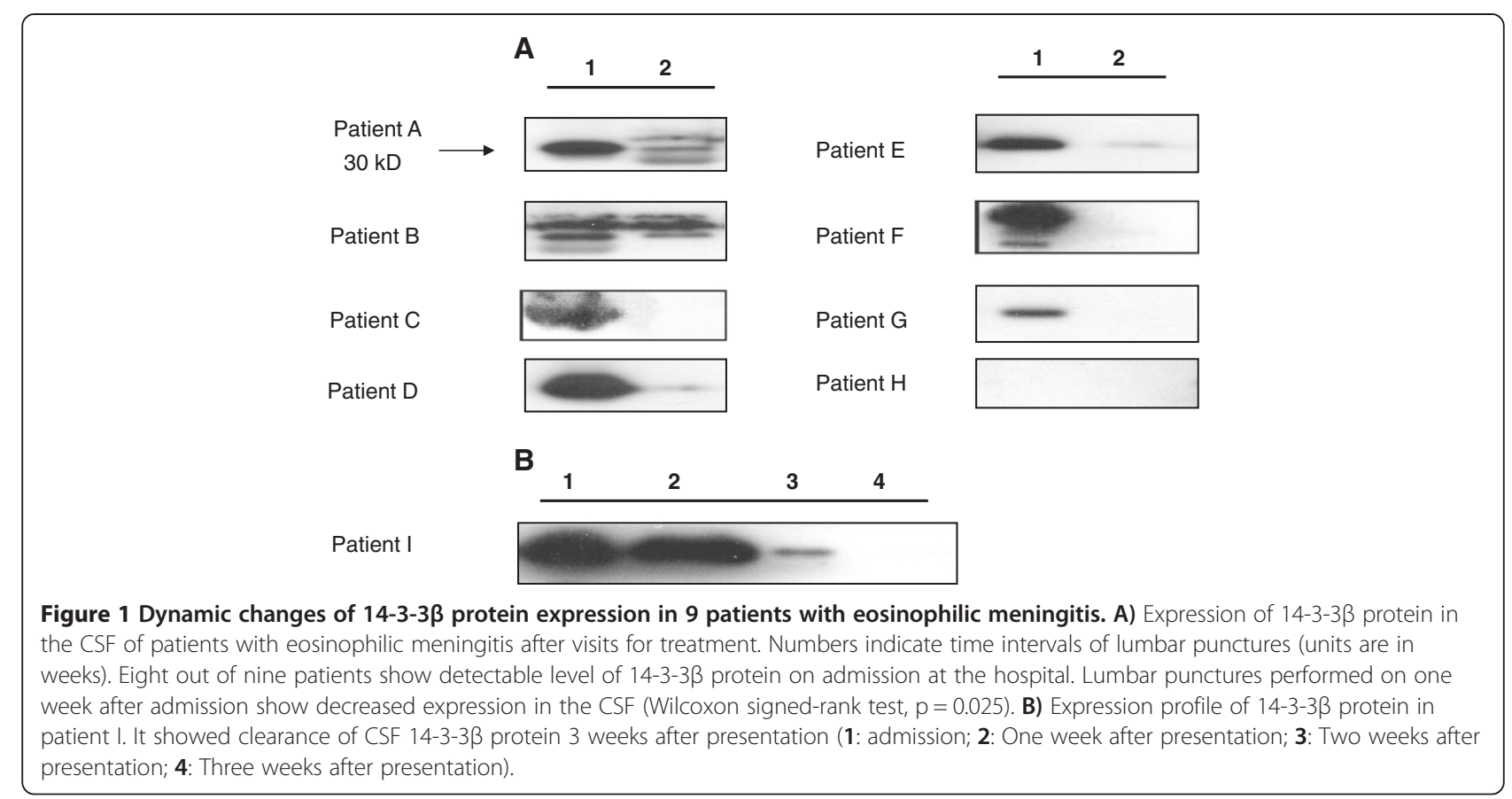

showed significantly increase 3 weeks after infection compared to those of uninfected mice $(\mathrm{p}=0.028)$ Figure 3 .

\section{Western blot analysis of $14-3-3 \beta$ protein in the CSF/serum} of mice

The Western blot analysis for $14-3-3 \beta$ protein expression in the CSF/serum of mice was shown in Figure 4. There was a significant increase of $14-3-3 \beta$ protein amounts of serum/CSF in the $3^{\text {rd }}$ week after infection compared to control. This finding was consistent the severity of blood brain barrier damage as evidence by the Evans Blue assay result.
Detection of $14-3-3 \beta$ levels in mice CSF/Serum samples by in house ELISA

Using polyclonal antibodies constructed from rabbit immunized with recombinant $14-3-3 \beta$ antigen, we have established a procedure to detect 14-3-3 $\beta$ levels in CSF and serum using ELISA. We found that the level of 14$3-3 \beta$ protein in the CSF/serum increased over a three week period after infection Figures 5 and 6 .

\section{Discussion}

We found that the amounts of CSF 14-3-3 $\beta$ protein were increased in our patients at presentation. After 2 weeks

Table 1 Initial 14-3-3 protein amount and laboratory and magnetic resonance imaging scan findings in 9 cases of eosinophilic meningitis caused by $A$. cantonensis

\begin{tabular}{|c|c|c|c|c|c|c|c|c|c|}
\hline \multirow[b]{2}{*}{ Patient } & \multicolumn{2}{|l|}{ Blood } & \multicolumn{5}{|c|}{ Cerebrospinal fluid } & \multirow[b]{2}{*}{$\begin{array}{c}\text { Headache } \\
\text { severity }\end{array}$} & \multirow[b]{2}{*}{ MRI } \\
\hline & $\begin{array}{l}\text { White blood cell count } \\
\qquad\left(\times 10^{3} / \mu \mathrm{L}\right)\end{array}$ & $\begin{array}{c}\text { Eosinophil } \\
(\%)\end{array}$ & $\begin{array}{l}\text { Protein } \\
(\mathrm{mg} / \mathrm{dL})\end{array}$ & $\begin{array}{l}\text { Glucose } \\
\text { (mg/dL) }\end{array}$ & $\begin{array}{l}\text { White blood cell count } \\
\qquad\left(\times 10^{3} / \mu \mathrm{L}\right)\end{array}$ & $\begin{array}{l}\text { Eosinophil } \\
\qquad \%)\end{array}$ & $\begin{array}{c}14-3-3 \beta \\
\text { Protein(DU) }\end{array}$ & & \\
\hline A & 8210 & 8 & 67 & 75 & 1 & 0 & 6.8 & 1 & ME, 1+ \\
\hline B & 7570 & 10 & 49 & 60 & 0 & 0 & 1.1 & 1 & $\mathrm{ME}, 1+$ \\
\hline C & 10500 & 36 & 154 & 36 & 1270 & 36 & 0 & 3 & ME, 3+ \\
\hline D & 6990 & 16 & 36 & 66 & 139 & 6 & 9.8 & 1 & $M E, 2+$ \\
\hline E & 5920 & 7 & 95 & 72 & 9 & 0 & 0 & 1 & $M E, 1+$ \\
\hline F & 9480 & 16 & 347 & 45 & 1660 & 6 & 7.8 & 3 & $\mathrm{ME}, 2+$ \\
\hline G & 6490 & 20 & 50 & 71 & 1 & 0 & 0 & 1 & $M E, 1+$ \\
\hline $\mathrm{H}$ & 8510 & 2 & 27 & 70 & 0 & 0 & 0 & 2 & $M E, 2+$ \\
\hline | & 13270 & 29 & 201 & 59 & 1390 & 17 & 5.1 & 3 & $\mathrm{ME}, 2+$ \\
\hline
\end{tabular}

ME: meningeal enhancement; MRI: magnetic resonance imaging; Severity of headache is graded as follows: 0 none, $1+$ mild, $2+$ moderate, $3+$ severe. The MRI grading is as follows: 0 none, $1+$ mild, $2+$ moderate, $3+$ high signal intensity in bilateral globus pallidus on T1 imaging. All of the 9 patients received only supportive treatment (acetaminophen and naproxen), lumbar puncture was done when clinically indicated. 


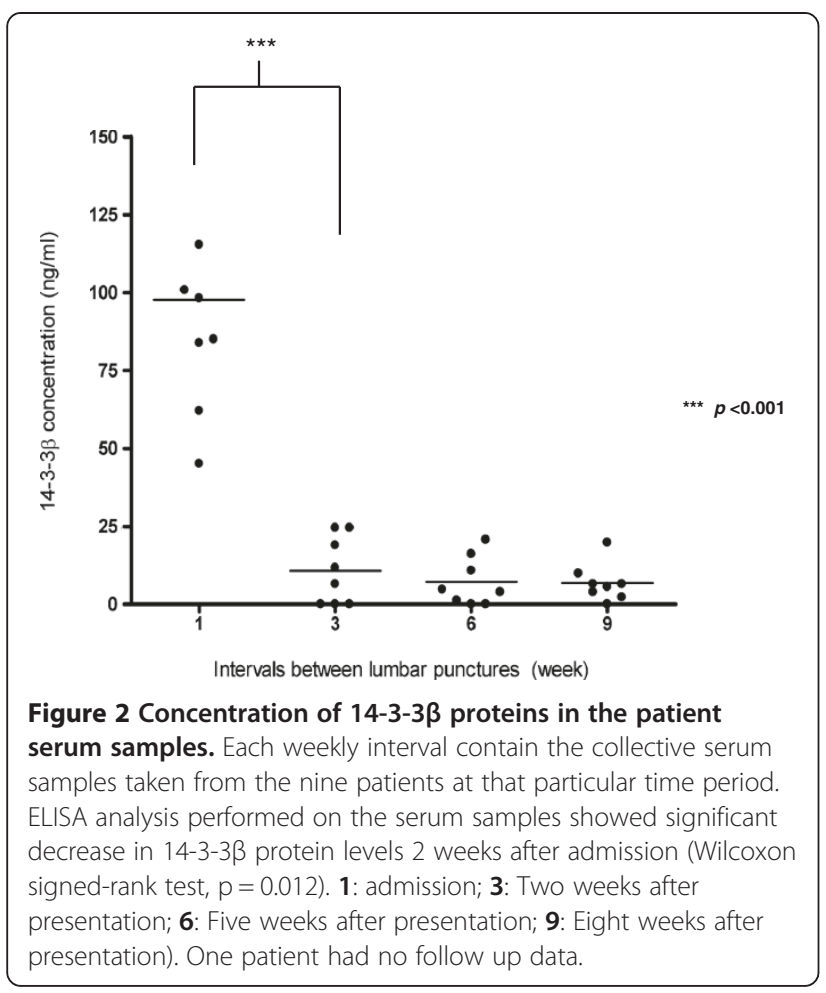

of treatment, all patients showed a declined level or cleared of 14-3-3 $\beta$ protein in the CSF. We also found that the serum 14-3-3 $\beta$ level was significantly increased in patients during initial visit by our in house ELISA. This probably indicated that the leakage of $14-3-3 \beta$ from the brain because of neuronal damage and blood brain barrier dysfunction. This finding was consistent to the animal experiment result in which there was severe

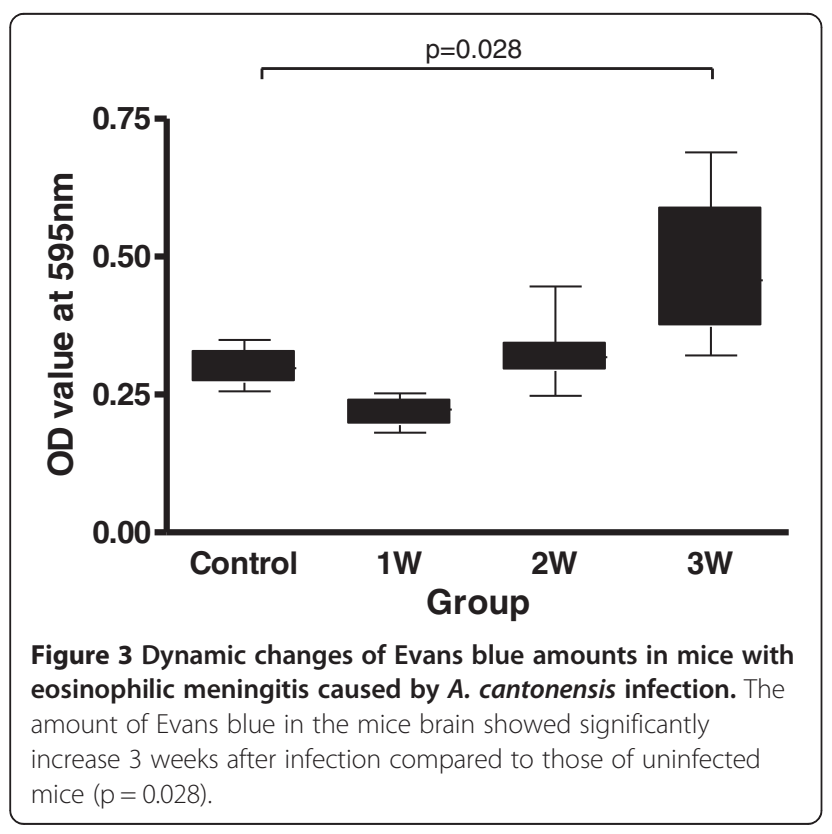

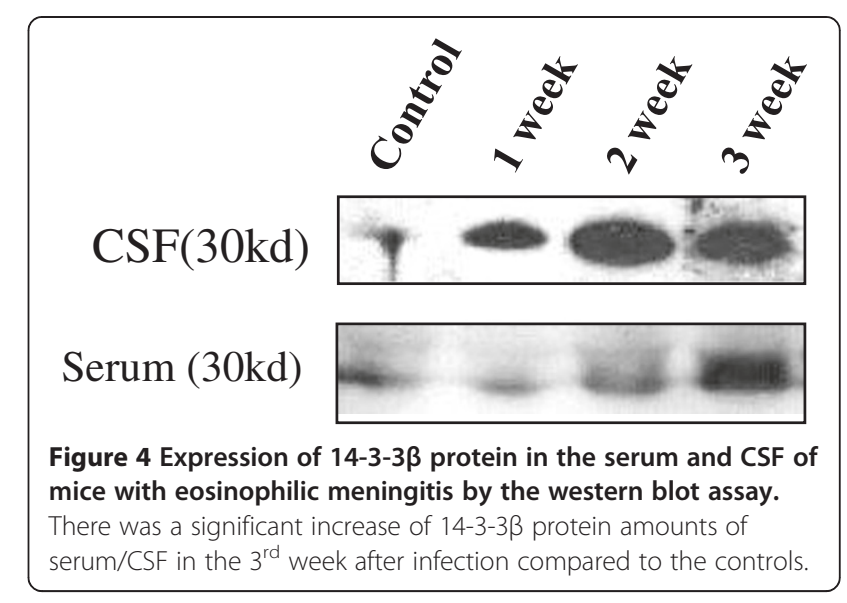

blood brain barrier damage three weeks after infection and increased 14-3-3 $\beta$ protein expression in the CSF and serum by western blot and in house ELISA.

The 14-3-3 proteins belong to a family of acidic, dimeric proteins that are expressed in all eukaryotic cells. This family of highly conserved proteins plays crucial roles in regulating multiple cellular processes including the maintenance of cell cycle checkpoints and DNA repair, the prevention of apoptosis, the onset of cell differentiation and senescence, and the coordination of cell adhesion and motility [21]. The highest tissue concentration of 14-3-3 proteins is found in the brain, comprising about $1 \%$ of its total soluble protein [22] and being present in the cytoplasmic compartments, plasma membrane and in intracellular organelles [23]. In addition to their possible role in neuronal function, 14-3-3 proteins have attracted much recent interest owing to their possible involvement in the pathophysiology of various neurological disorders [14-17,24]. However, there had been no reports in the literature that deal with the association of 14-3-3 protein and eosinophilic meningitis caused by $A$. cantonensis. In our cohort study, nine patients with eosinophilic meningitis, in addition to the commonly tested CSF parameters, were serially measured the CSF concentrations of $14-3-3 \beta$ proteins. Most of the patients $(8 / 9,90 \%)$ whom we investigated had a positive test result at admission, and all of those who recovered cleared 14-3-3 $\beta$ protein from CSF 2-3 weeks after hospitalization. This dynamic change of $14-3-3 \beta$ protein in CSF was consistent to the clinical course of recovery in our patients who received 2 weeks of treatment of painkiller and serial spinal tapping [9]. If 14-3$3 \beta$ proteins in CSF were used to monitor the evolution of a reversible condition, a marker of tissue damage must quickly clear once the damaging process has subsided, as in our cases.

We found a fairly good sensitivity of the 14-3-3 $\beta$ test. This result, however, had weak significance because they were based on only 9 patients with eosinophilic 


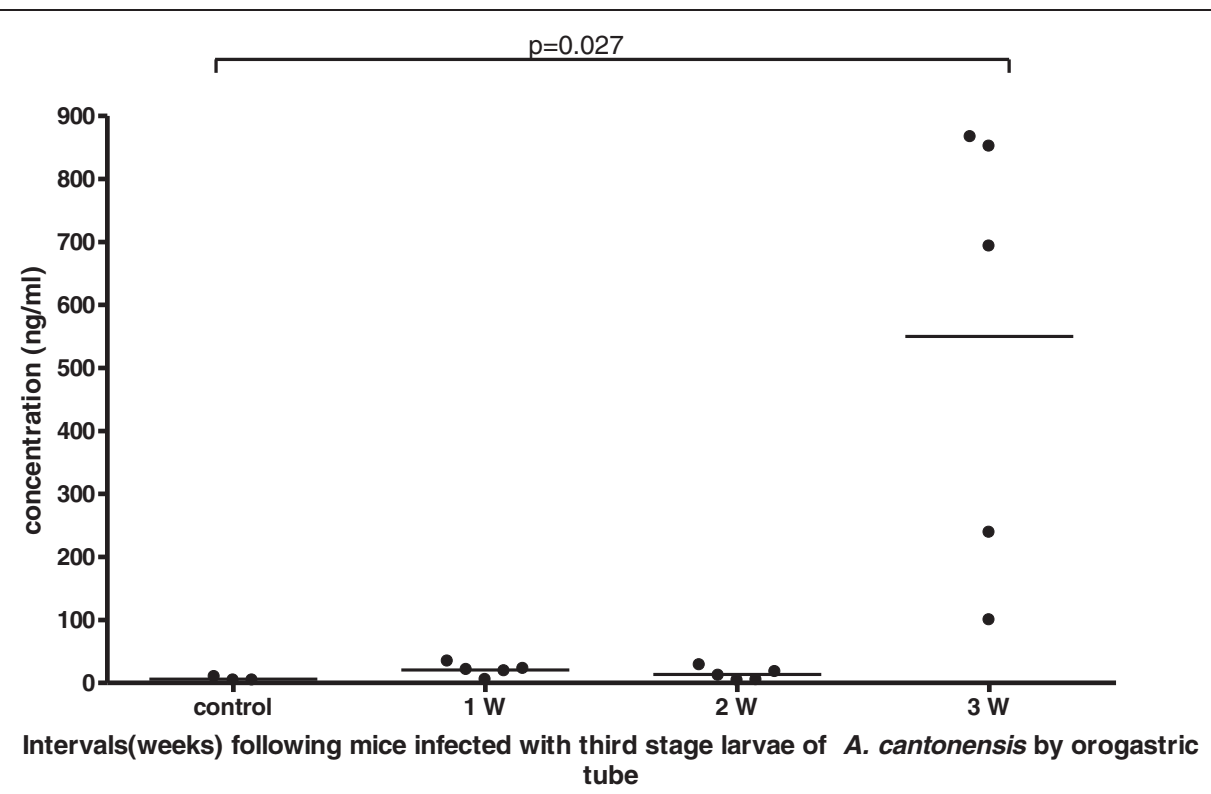

Figure 5 The levels of 14-3-3 $\beta$ protein in the CSF increased over a three week period after infection and the data was shown by an in house ELISA.

meningitis. But more importantly, we examined a homogenous population, regularly monitored CSF dynamic change and excluded patients with other neurological conditions such as other infectious encephalitis, dementia, brain tumor, metabolic encephalopathy, neuropathy and Creutzfeldt-Jakob disease, that would otherwise cause elevation of $14-3-3 \beta$ protein in CSF [12-17]. It has been shown that inappropriate handling and storage of CSF samples may alter the results of the test [13]. In our study, lumbar puncture techniques were optimal and identical in each case. The possible reason explaining the only one negative test result could be inappropriate handling and storage of CSF, technical problem, and threshold of 14-3-3 protein detection. Another most importantly reason was that the patient (patient $\mathrm{H}$ ) was diagnosed as $A$. cantonensis infection only based on

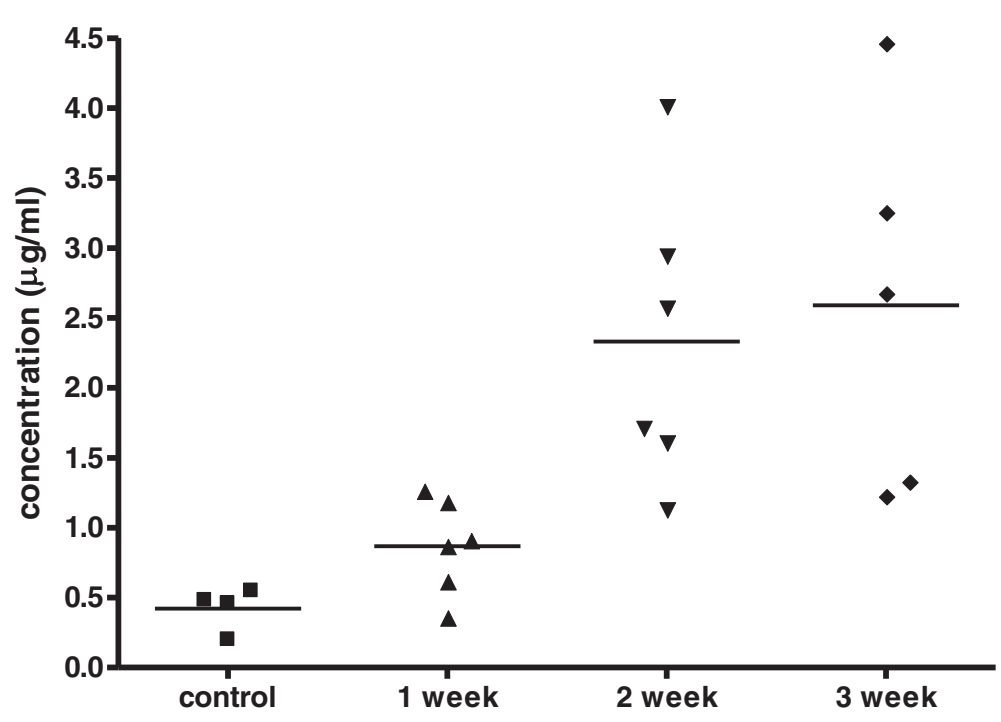

Figure 6 The levels of 14-3-3 $\beta$ protein in the serum increased over a three week period after infection and the data was shown by an in house ELISA. 
the exposure history and positive serum serology. He had no peripheral eosinophilia or CSF abnormalities which are commonly seen in patients with eosinophilic meningitis caused by $A$. cantonensis infection. Finally, the time interval between disease onset and the 14-3-3 3 test was similar in the eosinophilic meningitis group and control group (13 vs.12 days, respectively), suggesting that disease duration alone cannot account for the dynamic change of 14-3-3 $\beta$ protein in CSF. Taken together, our data suggest that, when performed as a screening test in a patient with eosinophilic meningitis, a positive $14-3-3 \beta$ test result may rule in this diagnosis. Another matter of concern comes from the questionable reliabil-

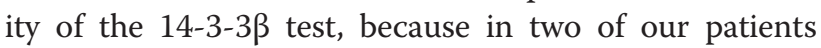
with relapse (patient $\mathrm{C}, \mathrm{I}$ ), the result was found to be first positive and then only weakly positive when relapse occurred. This situation does not seem to be unique because it has already been observed by others in four non-CJD patients who were initially found positive and then negative 2 weeks later [25]. Possible explanations include instability of the $14-3-3 \beta$ protein in the sample over time, or clinical recurrence of symptoms/signs which did not cause ongoing neuronal damage. To solve these issues, further controlled, multicenter studies assessing the validity of the $14-3-3 \beta$ test are needed.

Identification of 14-3-3 proteins in CSF of patients afflicted with a wide range of neuro-degenerative diseases has been well documented $[17,26]$, however there is few literatures which discuss the presence of such protein in the serum. In the current study, we presented the in-house ELISA as another diagnostic mean to validate the western blot analysis of 14-3-3 $\beta$ proteins in the CSF and serums samples collected. We found that there was a significant decrease in serum 14-3-3 $\beta$ level from onset of meningitis to two weeks after admission to the hospital, and so on until $8^{\text {th }}$ week. However, there were no significant changes in CSF 14-3-3 $\beta$ levels between each lumbar puncture intervals as opposed to results from western blot. It is likely that limited CSF sample numbers and inadequate CSF volumes for ELISA contributed to such discrepancy, as the results from ELISA would be less accurate and sensitive if there weren't enough samples available for analysis.

The presence of $14-3-3 \beta$ proteins in serum samples may be the consequences of disruption of the blood brain barrier caused by the meningitis, as it was shown that infection by the parasite may induce up-regulation of inflammatory agents such as MMP-9 [27], and contributes to the degradation of meningeal blood vessel membranes. This change in the cerebral vasculature could account for the leakage of 14-3-3 $\beta$, primarily a CNS protein, into the peripheral circulation. In terms of clinical application, the ability to detect $14-3-3 \beta$ proteins in serum samples may yield potential diagnostic values such ease of sample acquisition, reduced discomfort for patients undergoing diagnosis and increased efficiency in sample handling/detection. However, the current technique may require additional refinements to increase its sensitivity and accuracy before it could be implemented as an alternative diagnostic tool of neurodegenerative disease.

\section{Conclusion}

The current study found that patients with eosinophilic meningitis and presence of $14-3-3 \beta$ proteins in CSF tended to have more severe CSF laboratory abnormalities. The decline of $14-3-3 \beta$ proteins $2-3$ weeks after admission was consistent with the idea that 14-3-3 protein levels are associated with the pace of neuronal injury.

\section{Competing interests}

The authors declare that they have no competing interests.

\section{Authors' contributions}

Conceived and designed the experiments: HCT, YSC, and MHT. Performed the experiments: YLH, and RT. Analyzed the data: CMY and SSJL. Wrote the paper: HCT, YSC, and MHT. All authors read and approved the final manuscript.

\section{Acknowledgments}

This work is supported by grant VGHKS96-027 from Kaohsiung Veterans General Hospital, and grant 97-2320-B-075B-001-MY2 from the National Science Council, Republic of China. The funders had no role in study design, data collection and analysis, decision to publish, or preparation of the manuscript. Presented in part in $60^{\text {th }}$ Annular Meeting of American Society of Tropical Medicine and Hygiene, Philadelphia, December 4-8, 2011

\section{Author details}

${ }^{1}$ Section of Infectious Diseases, Department of Medicine, Kaohsiung Veterans General Hospital, 386, Ta-Chung 1st Road, Kaohsiung 813, Taiwan. ${ }^{2}$ National Yang-Ming University, Taipei, Taiwan. ${ }^{3}$ Institute of Biomedical Sciences, National Sun Yat-Sen University, Kaohisung, Taiwan, Republic of China. ${ }^{4}$ Department of Parasitology and Graduate Institute of Medicine, Kaohsiung Medical University, Kaohsiung, Taiwan.

Received: 22 March 2013 Accepted: 11 February 2014

Published: 20 February 2014

\section{References}

1. Beaver PC, Rosen $L$ : Memorandum on the first report of angiostrongylus in man, by Nomura and Lin, 1945. Am J Trop Med Hyg 1964, 13:589-590.

2. Punyagupta S, Juttijudata P, Bunnag T: Eosinophilic meningitis in Thailand: clinical studies of 484 typical cases probably caused by Angiostrongylus cantonensis. Am J Trop Med Hyg 1975, 24:921-931.

3. Rosen $L$, Chappell $R$, Laqueur G: Eosinophilic meningoencephalitis caused by a metastrongylid lung worm of rats. JAMA 1962, 179:620-624.

4. Yii CY: Clinical observations on eosinophilic meningitis and meningoencephalitis caused by Angiostrongylus Cantonensis on Taiwan. Am J Trop Med Hyg 1976, 25:233-249.

5. Wen Y: Distribution patterns of Angiostrongylus cantonensis in Achatina fulica. Chinese J Microbiol 1973, 6:1-10.

6. Nishimura K, Mogi M, Okazaw T: Angiostrongylus cantonensis infection in Ampullarium canaliculatus in Kyusu, Japan. Southeast Asian J Trop Med Pub Health 1986, 17:595-600.

7. Richards C, Merritt J: Studies on Angiostrongylus cantonensis in molluscan intermediate hosts. J Parasitol 1967, 53:382-388.

8. Yen CM, Chen ER, Cheng CW: A survey of Ampullarium canaliculatus for natural infection of Angiostrongylus cantonensis in south Taiwan. J Trop Med Hyg 1990, 93:347-350. 
9. Tsai HC, Liu YC, Kunin CM, Lee SJ, Chen YS, Lin HH, Tsai TH, Lin WR, Huang CK, Yen MY, Yen CM: Eosinophilic meningitis caused by Angiostrongylus cantonensis: report of 17 cases. Am J Med 2001, 111:109-114.

10. Tsai HC, Liu YC, Kunin CM, Lai PH, Lee SS, Chen YS, Wann SR, Lin WR, Huang $C K$, Ger LP, Lin HH, Yen MY: Eosinophilic meningitis caused by Angiostrongylus Cantonensis associated with eating raw snails: correlation of brain magnetic resonance imaging scans with clinical findings. Am J Trop Med Hyg 2003, 68:281-285.

11. Tsai HC, Lee SJ, Huang CK, Yen CM, Chen ER, Liu YC: Outbreak of eosinohilic miningitis associated with drinking raw vegetable juice in southern Taiwan. Am J Trop Med Hyg 2004, 71:222-226.

12. Hsich G, Kenney K, Gibbs CJ, Lee KH, Harrington MG: The 14-3-3 brain protein in cerebrospinal fluid as a marker for transmissible spongiform encephalopathies. N Engl J Med 1996, 335:924-930.

13. Aksamit AJ: Cerebrospinal fluid 14-3-3 protein: variability of sporadic creutzfeldt-jakob disease, laboratory standards, and quantitation. Arch Neurol 2003, 60:803-804.

14. Collins S, Boyd A, Fletcher A, Gonzales M, McLean CA, Byron K, Masters CL: Creutzfeldt-Jakob disease: diagnostic utility of 14-3-3 protein immunodetection in cerebrospinal fluid. J Clin Neurosci 2000, 7:203-208.

15. Haïk S, Brandel JP, Sazdovitch V, Delasnerie-Lauprêtre N, Peoc'h K, Laplanche JL, Privat N, Duyckaerts C, Kemeny JL, Kopp N, Laquerrière A, Mohr M, Deslys JP, Dormont D, Hauw JJ: Dementia with Lewy bodies in a neuropathologic series of suspected Creutzfeldt-Jakob disease. Neurology 2000, 55:1401-1404.

16. Miller RF, Green AJE, Giovannoni G, Thompson EJ: Detection of 14-3-3 brain protein in cerebrospinal fluid of HIV infected patients. Sex Transm Infect 2000, 76:408

17. Irani DN, Kerr DA: 14-3-3 protein in the cerebrospinal fluid of patients with acute transverse myelitis. Lancet 2000, 355:901.

18. Morassutti AL, Levert K, Perelygin A, da Silva AJ, Wilkins $P$, Graeff-Teixeira C: The 31-kDa antigen of Angiostrongylus cantonensis comprises distinct antigenic glycoproteins. Vector Borne Zoonotic Dis 2012, 12:961-968.

19. Chye SM, Chang JH, Yen CM: Immunodiagnosis of human eosinophilic meningitis using an antigen of Angiostrongylus cantonensis L5 with molecular weight 204 kD. Acta Trop 2000, 75:9-17.

20. Hu TH, Huang CC, Liu LF, Lin PR, Liu SY, Chang HW, Changchien CS, Lee $\mathrm{CM}$, Chuang JH, Tai MH: Expression of hepatoma-derived growth factor in hepatocellular carcinoma. Cancer 2003, 98:1444-1456.

21. Berg D, Holzmann C, Riess O: 14-3-3 proteins in the nervous system. Nat Rev Neurosci 2003, 4:752-762

22. Boston PF, Jackson P, Thompson RJ: Human 14-3-3 protein: radioimmunoassay, tissue distribution, and cerebrospinal fluid levels in patients with neurological disorders. J Neurochem 1982, 38:1475-1482.

23. Fu H, Subramanian RR, Masters SC: 14-3-3 proteins: structure, function, and regulation. Annu Rev Pharmacol Toxicol 2000, 40:617-647.

24. Bonora S, Zanusso G, Raiteri R, Monaco S, Rossati A, Ferrari S, Boffito M, Audagnotto S, Sinicco A, Rizzuto N, Concia E, Di Perri G: Clearance of 14-3-3 protein from cerebrospinal fluid heralds the resolution of bacterial meningitis. Clin Infect Dis 2003, 36:1492-1495

25. Zerr I, Bodemer M, Gefeller O: Detection of 14-3-3 protein in the cerebrospinal fluid supports the diagnosis of Creutzfeldt-Jakob disease. Ann Neurol 1998, 43:32-40.

26. Lu CH, Chang WN, Chang HW, Chung K, Tsai HC, Wang HC, Chen SS, Chuang YC, Huang CR, Tsai NW, Chiang YF: The value of serial cerebrospinal fluid 14-3-3 protein levels in adult community-acquired bacterial meningitis. QJM 2008, 101:225-230.

27. Chen KM, Lee HH, Lu KH, Tseng YK, Hsu LS, Chou HL, Lai SC: Association of matrix metalloproteinase-9 and Purkinje cell degeneration in mouse cerebellum caused by Angiostrongylus cantonensis. Int J Parasitol 2004, 34:1147-1156.

doi:10.1186/1756-0500-7-97

Cite this article as: Tsai et al:: 14-3-3 $\beta$ protein expression in eosinophilic meningitis caused by Angiostrongylus cantonensis infection. BMC Research Notes 2014 7:97.

\section{Submit your next manuscript to BioMed Central and take full advantage of:}

- Convenient online submission

- Thorough peer review

- No space constraints or color figure charges

- Immediate publication on acceptance

- Inclusion in PubMed, CAS, Scopus and Google Scholar

- Research which is freely available for redistribution

Submit your manuscript at www.biomedcentral.com/submit
() Biomed Central 